Author: Arkadiusz Trąbka

Title of article: „Wpływ sposobu posadowienia młotów kuźniczych na ich kinematykę i dynamikę” (“Influence of foundation types on kinematics and dynamics of forging hammers")

Mechanik, Vol. 91, No. 10 (2018): pages 830-832

DOI: https://doi.org/10.17814/mechanik.2018.10.137

\title{
Influence of foundation types on kinematics and dynamics of forging hammers
}

\author{
Wpływ sposobu posadowienia młotów kuźniczych \\ na ich kinematykę i dynamikę
}

\section{ARKADIUSZ TRĄBKA *}

In the paper the influence of foundation types on kinematics and dynamics of forging hammers was analyzed. Three types of foundations for forging hammers were compared. Computational models were analyzed numerically in the Matlab program. It was established which type of foundation provides the most favorable working conditions for forging hammers. Restrictions on the use of hammers depending on the type of foundation were also indicated.

KEYWORDS: foundations for forging hammers, computational models, kinematics and dynamics of forging hammers

Forging hammers are devices whose operation is accompanied by the occurrence of very high dynamic loads and vibrations of significant amplitudes. Due to the abovementioned impacts, the hammers must be placed on specially designed supporting structures. The purpose of these structures is to effectively reduce both the creation of dynamic loads and their transfer to the ground [1, 4, 7, 10, 12].

Based on experimental investigations and analyses of computational models, various concepts for making foundations for forging hammers were developed $[3,7,8,10]$. The most common foundations are found in Fig. 1.

A number of analyses have been carried out with regard to particular foundation methods [1, 2, 4-7, 9, 11, 12]. In none of the checked literature items, however, a study containing a direct comparison of foundation methods presented in Fig. 1 was found. The authors of the article decided to fill this gap and compare different hammer-foundation-soil dynamic systems to establish which foundation provide the most favorable working conditions for forging hammers.

In order to obtain unambiguous comparative results, it was decided that the hammer of the so-called average characteristic values, for which realized mountings on each of the considered types of foundations are known, will be the object of the analyses. The object that meets these requirements is the steam-air die forging hammer type MPM $10000 \mathrm{~B}$ [9].

\section{Physical models of considered dynamic systems}

Development of computational models began with the assumptions simplifying the real structures, resulting in their physical models (Fig. 2). In the process of replacing the real structures with physical models, it was assumed, among others, that the hammer, the foundation block and the foundation trough are coaxially positioned, non-deformable material solids with a possible rectilinear relative motion. The Kelvin-Voigt body fulfills the role of constraints for particular solids. The constraints are considered as weightless. Experimentally or computationally determined stiffness and damping with linear characteristics are assigned to the constraints. The subsoil for the foundation, according to the technical model of Savinov [7], is treated as an element with elastic-damping properties. The subsoil properties are represented by stiffness and damping with linear characteristics.

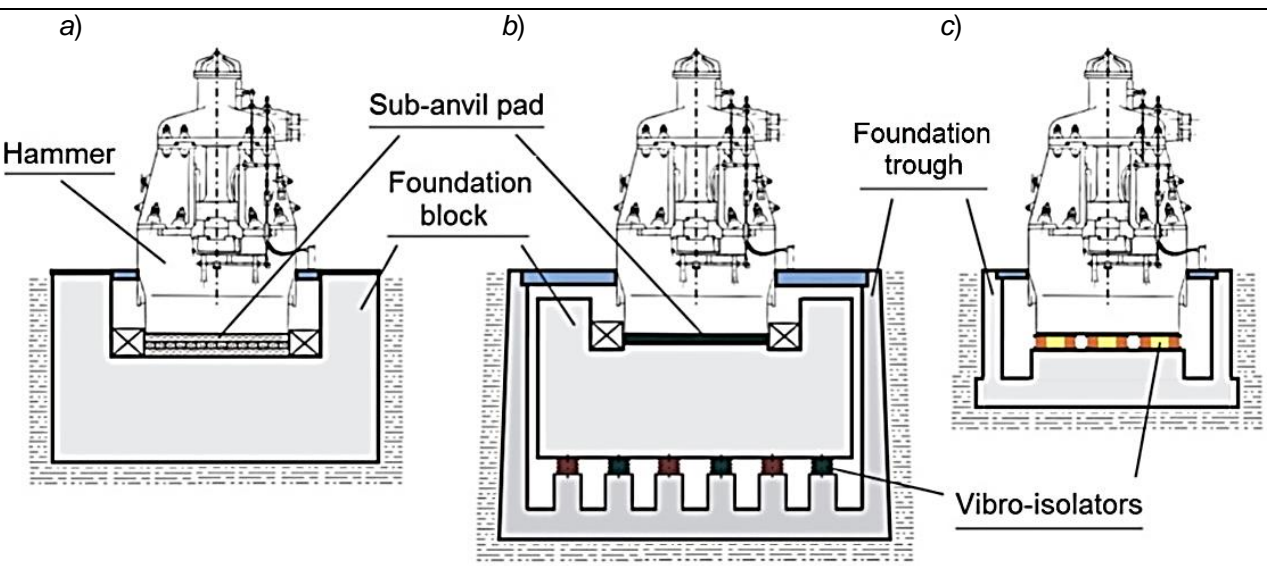

Fig. 1. Types of foundations for forging hammers: a) reinforced concrete foundation block placed directly on the ground (foundation type $A$ ), b) reinforced concrete foundation block based on spring-rubber isolation system in a reinforced concrete foundation trough (foundation type $B$ ), c) direct foundation of a hammer on viscous-spring isolation system in a reinforced concrete foundation trough (foundation type $C$ ) 
a)

b)
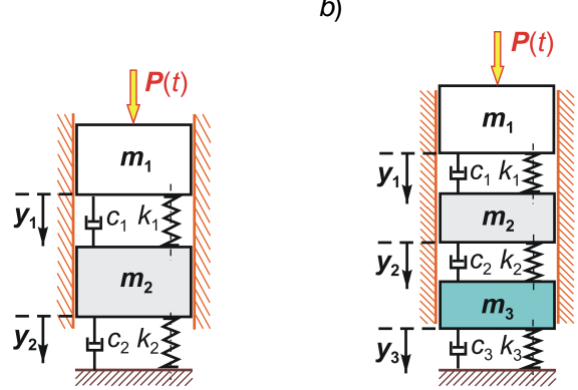

Fig. 2. Physical models of considered hammer-foundation-soil dynamic systems: a) model corresponding to foundations type $A$ and $C, b)$ model corresponding to foundation type $B$

\section{Mathematical models and their parameters}

The mathematical model of the system consisting of two mass elements (Fig. 2a) was written in the form of motion equations, which were derived based on d'Alembert's principle for the case of forced damped vibrations:

$$
\begin{gathered}
m_{1} \cdot \ddot{y}_{1}+c_{1} \cdot\left(\dot{y}_{1}-\dot{y}_{2}\right)+k_{1} \cdot\left(y_{1}-y_{2}\right)=P(t) \\
m_{2} \cdot \ddot{y}_{2}+c_{1} \cdot\left(\dot{y}_{2}-\dot{y}_{1}\right)+k_{1} \cdot\left(y_{2}-y_{1}\right)+ \\
+c_{2} \cdot \dot{y}_{2}+k_{2} \cdot y_{2}=0
\end{gathered}
$$

where: $m_{1}$ - the hammer mass; $m_{2}$ - mass of the foundation block (Fig. 1a) or the foundation trough (Fig. 1c); $c_{1}$ damping coefficient of the sub-anvil pad (Fig 1a) or vibroisolators (Fig. 1c); $c_{2}-$ damping coefficient of the soil; $k_{1}-$ stiffness of the sub-anvil pad (Fig. 1a) or vibro-isolators (Fig. $1 c) ; k_{2}$ - stiffness of the soil; $P(t)$ - time course of the impact force; $\ddot{y}_{\mathrm{i}}, \dot{y}_{\mathrm{i}}, y_{\mathrm{i}}-$ acceleration, velocity and displacement of the $i$-th mass $(i=1,2)$, respectively.

For the system consisting of three mass elements (Fig. $2 b$ ), the mathematical model was written in the form of motion equations:

$$
\begin{aligned}
& m_{1} \cdot \ddot{y}_{1}+c_{1} \cdot\left(\dot{y}_{1}-\dot{y}_{2}\right)+k_{1} \cdot\left(y_{1}-y_{2}\right)=P(t) \\
& m_{2} \cdot \ddot{y}_{2}+c_{1} \cdot\left(\dot{y}_{2}-\dot{y}_{1}\right)+k_{1} \cdot\left(y_{2}-y_{1}\right)+ \\
& +c_{2} \cdot\left(\dot{y}_{2}-\dot{y}_{3}\right)+k_{2} \cdot\left(y_{2}-y_{3}\right)=0 \\
& m_{3} \cdot \ddot{y}_{3}+c_{2} \cdot\left(\dot{y}_{3}-\dot{y}_{2}\right)+k_{2} \cdot\left(y_{3}-y_{2}\right)+ \\
& \quad+c_{3} \cdot \dot{y}_{3}+k_{3} \cdot y_{3}=0
\end{aligned}
$$

where: $m_{1}, m_{2}, m_{3}$ - masses of: the hammer, foundation block and foundation trough, respectively; $c_{1}, c_{2}, c_{3}$ - damping coefficients of: the sub-anvil pad, vibro-isolators and soil, respectively; $k_{1}, k_{2}, k_{3}$ - stiffness of: the sub-anvil pad, vibro-isolators and soil, respectively; $P(t)$ - time course of the impact force; $\ddot{y}_{\mathrm{i}}, \dot{y}_{\mathrm{i}}, y_{\mathrm{i}}-$ acceleration, velocity and displacement of the $i$-th mass $(i=1,2,3)$, respectively.

The time course of the impact force was adopted in the form of a rectangular pulse $[1,7]$ :

$$
P(t)=\left\{\begin{array}{llr}
P_{\mathrm{m}}=\frac{S}{\tau}=\frac{(1+R) \cdot \sqrt{2 \cdot U \cdot m_{\mathrm{B}}}}{\tau} & \text { when } & 0 \leq t \leq \tau \\
0 & \text { when } & t>\tau
\end{array}\right.
$$

where: $P_{\mathrm{m}}$ - maximum value of the impact force, $S$-size of the pulse load, $T$ - the load duration, $R$ - coefficient of restitution, $U$ - full hammer energy, $m_{\mathrm{B}}$-mass of a ram.

Differential equations of motion (1) and (2) were solved numerically in the Matlab program. The integration of the equations was made using the fourth order Runge-Kutta technique and own calculation scripts.

\begin{tabular}{|c|c|c|c|c|}
\hline \multirow{2}{*}{ Parameter } & \multirow{2}{*}{ Symbol } & \multicolumn{3}{|c|}{ Foundation type } \\
\hline & & $\bar{A}$ & $B$ & $C$ \\
\hline \multirow{3}{*}{$\begin{array}{l}\text { Mass, } \\
\mathrm{kg}\end{array}$} & $m_{1}$ & 103000 & 103000 & 103000 \\
\hline & $m_{2}$ & 265213 & 402780 & 97152 \\
\hline & $m_{3}$ & & 336882 & \\
\hline \multirow[b]{2}{*}{$\begin{array}{l}\text { Stiffness, } \\
\mathrm{N} / \mathrm{m}\end{array}$} & $k_{1}$ & $6717 \cdot 10^{6}$ & $9300 \cdot 10^{6}$ & $114 \cdot 10^{6}$ \\
\hline & $\begin{array}{l}k_{2} \\
k_{3}\end{array}$ & $5766 \cdot 10^{6}$ & $\begin{array}{c}506 \cdot 10^{6} \\
9600 \cdot 10^{6}\end{array}$ & $3744 \cdot 10^{6}$ \\
\hline \multirow{3}{*}{$\begin{array}{l}\text { Damping, } \\
\mathrm{N} \cdot \mathrm{s} / \mathrm{m}\end{array}$} & $c_{1}$ & $1.298 \cdot 10^{6}$ & $4.63 \cdot 10^{6}$ & $1.716 \cdot 10^{6}$ \\
\hline & $c_{2}$ & $9.387 \cdot 10^{6}$ & $2.724 \cdot 10^{6}$ & $5.577 \cdot 10^{6}$ \\
\hline & $c_{3}$ & & $18.32 \cdot 10^{6}$ & \\
\hline
\end{tabular}

The parameters of the models were determined on the basis of the data characterizing the real steam-air die forging hammer type MPM 10000 B and the real, implemented foundation methods. When the soil parameters were determined, it was assumed that all foundations rest on the soil with the same properties. A list of parameters for the computational models is provided in the table.

\section{TABLE. Parameters of computational models}

\section{Results and discussion}

In order to determine how the selected dynamic and kinematic parameters of the forging hammers are influenced by particular foundation methods, a single hit of the ram of mass $m_{B}=4950 \mathrm{~kg}$ in a forged material was analyzed. It was assumed that the impact occurs with the maximum kinetic energy $U=110 \cdot 10^{3} \mathrm{~J}$, and the coefficient of restitution $R=$ 0.8 , which corresponds to the hardest works performed on die forging hammers [4].

The calculations were carried out for the maximum force $P_{\mathrm{m}}=59.4 \cdot 10^{6} \mathrm{~N}$, the value of which was calculated on the basis of equation (3), assuming that the load duration $T=0.001 \mathrm{~S}$.

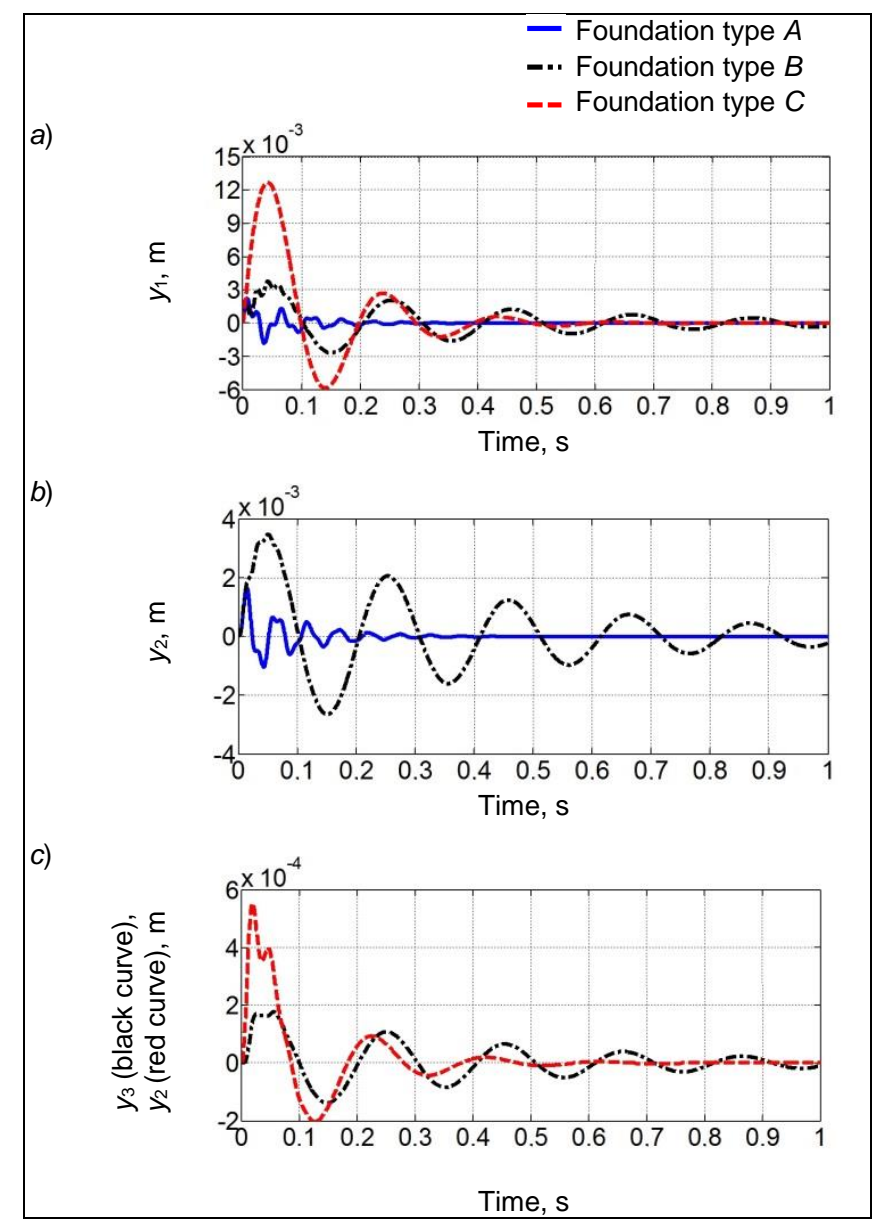

Fig. 3. Time histories of displacements of: a) the hammer $y_{1}$, $b$ ) the foundation block $y_{2}$ (for foundations type $A$ and $B$ ), c) the foundation trough $y_{3}$ (for foundation type $B$ ) and $y_{2}$ (for foundation type $C$ ) 

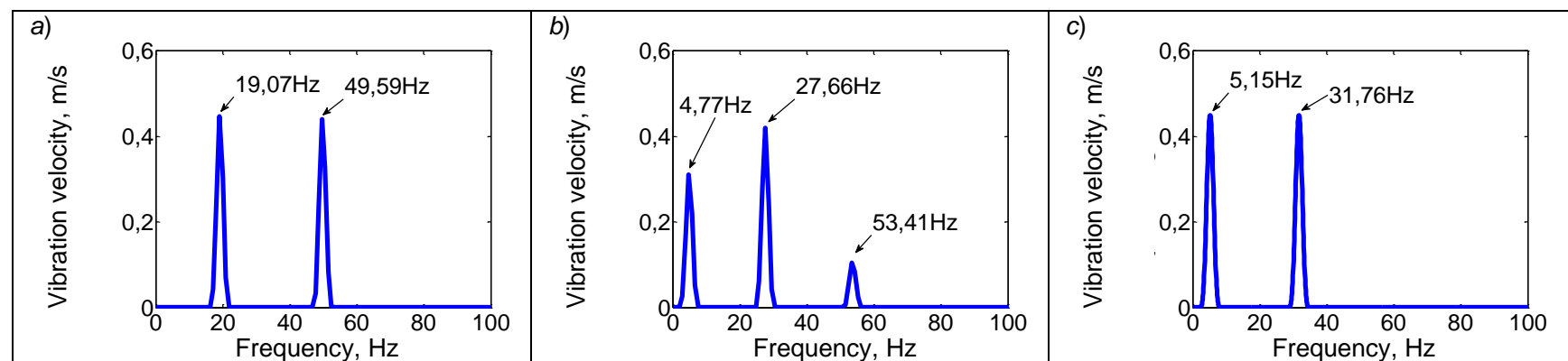

Fig. 4. Amplitude spectra of vibration velocity for models corresponding to foundations: a) type $A$, b) type $B$, c) type $C$

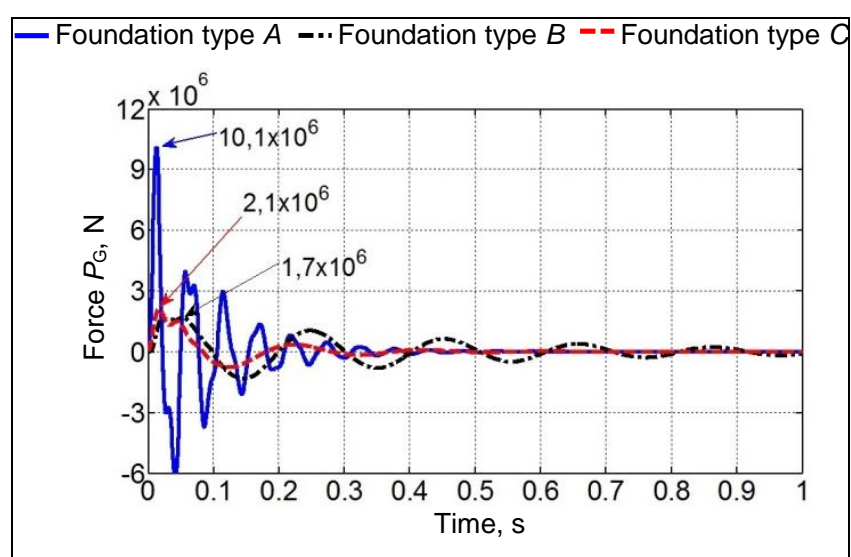

Fig. 5. Time histories of forces transmitted to the ground

For each type of foundation, time histories of displacements, velocities and accelerations of vibrations of the hammer and the foundation block and/or the foundation trough have been determined.

From time histories of displacements (Fig. 3) it was read that the smallest displacement of the hammer occurs for the foundation type $A$. In turn, the largest hammer displacements (almost six times greater than for foundation type $A$ ) appear immediately after the impact of the ram in the case of foundation type $C$. Only for foundations type $A$ and $B$ the displacement of the hammer does not exceed the permissible values, i.e. $4 \mathrm{~mm}[4,6]$.

Regarding the foundation block (foundation type $A$ ) it was found that its maximum displacement is $41 \%$ greater than the permissible one (1.2 $\mathrm{mm}$ according to $[6,7,10])$ for this type of foundations. Exceeding the permissible level of vibration amplitudes was also found in the case of the foundation type $C$ - the maximum displacement of the foundation trough turned out to be higher than the permissible one $0.2 \mathrm{~mm}$ according to $[7,10])$ by as much as $175 \%$. Only for the foundation type $B$, the level of permissible amplitudes was not exceeded.

Using the fast Fourier transformation (FFT), spectral characteristics of the vibration velocity (Fig. 4) were made, and then the natural frequency of vibration of the considered dynamic systems were read out. It was found that the basic natural frequency of vibration only for foundations type $B$ and $C$ is in the range of $2 \div 6 \mathrm{~Hz}$, which is recommended for this type of structures [7].

The dynamic loads of the soil are presented in Fig. 5. It was found that the soil lowest dynamic loads occur for the foundation type $B$. The forces transferred to the ground by the foundation type $C$ are greater by $23.5 \%$, while the foundation type $A$ acts on the ground with almost six times greater force than that found for the foundation type $B$.

\section{Conclusions}

The article discusses the influence of applied type of foundation (Fig. 1) on selected dynamic quantities and kinematic parameters of forging hammers.
On the basis of the analyses of models of hammerfoundation-soil dynamic systems it was found that the most favorable working conditions ensure mounting of the hammer on a foundation consisting of: a sub-anvil pad, reinforced concrete block, vibro-isolator and reinforced concrete foundation trough (foundation type $B$ ). Maximum displacement amplitudes only for this type of foundation did not exceed the permissible values. Mounting the hammer on a foundation type $B$ ensures at the same time the lowest dynamic load of the ground.

In addition, it was found that hammers placed on foundations type $A$ and $C$ (Fig. 1) should not be used for heavy forging works (in the case of the foundation type $A-$ mainly due to the very high dynamic loads of the ground, while in the case of the foundation type $C$-due to excessive vibrations both the foundation trough and the hammer).

\section{REFERENCES}

1. Chehab A.G., El Naggar M.H. "Design of efficient base isolation for hammers and presses". Soil Dynamics and Earthquake Engineering. 23 (2003): pp. 127-141.

2. Chehab A.G., El Naggar M.H. "Response of block foundations to impact loads". Journal of Sound and Vibration. 276, 1-2 (2004): pp. 293-310.

3. Dembiński M. „Nowe tendencje w kształtowaniu fundamentów młotów matrycowych". Mechanik. 12 (1996): p. 543.

4. Dresig H., Holzweißig F. "Dynamics of machinery". Berlin, Heidelberg: Springer-Verlag, 2010.

5. El Hifnawy L., Novak M. "Response of hammer foundations to pulse loading". International Journal of Soil Dynamics and Earthquake Engineering. 3, 3 (1984): pp. 124-132.

6. Heidari M., El Naggar M.H. "Using reinforced soil systems in hammer foundations". Proceedings of the Institution of Civil Engineers. Gl2 (2010): pp. 121-132.

7. Lipiński J. „Fundamenty pod maszyny”. Warszawa: Wyd. Arkady, 1985.

8. Łańczak W., Penno M. „Nowe sposoby kształtowania i posadowienia fundamentów młotów kuźniczych". Mechanik. 6 (1979): pp. 325-330.

9. Majewski L., Trabka A. "Assessment of dynamical properties of die hammer MPM 10000 B considering deformations of working material". Solid State Phenomena. 144 (2009): pp. 71-76.

10. Major A. "Dynamics in civil engineering - analysis and design volume If'. Budapest: Akademiai Kiado, 1980.

11. Novak M., El Hifnawy L. "Vibration of hammer foundations". International Journal of Soil Dynamics and Earthquake Engineering. 2, 1 (1983): pp. 43-53.

12. Wang G., Dong Z. "Design optimization of low impact transmission foundation for forging hammers". Engineering Computations. 23, 2 (2006): pp. 166-186.

Translation of scientific articles, their computer composition and publishing them on the website www.mechanik.media.pl by original articles in Polish is a task financed from the funds of the Ministry of Science and Higher Education designated for dissemination of science.

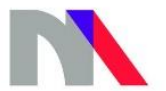

